\title{
FASES DO PROCESSO DE RECONHECIMENTO DE CURSOS SUPERIORES O CASO DO INSTITUTO FEDERAL FARROUPILHA
}

\begin{tabular}{c}
\hline PHASES THE PROCESS OF RECOGNITION OF DEGREE COURSES \\
THE CASE OF THE FEDERAL INSTITUTE FARROUPILHA \\
\hline FASES DEL PROCESO DE RECONOCIMIENTO DE CARRERAS UNIVERSITARIAS \\
EL CASO DEL INSTITUTO FEDERAL FARROUPILHA
\end{tabular}

\section{Antônio Carlos Minussi Righes' Mônica de Souza Trevisan ${ }^{2}$ Rosane Carneiro Sarturi ${ }^{3}$ Marilene Gabriel Dalla Corte}

\begin{abstract}
RESUMO: Este artigo tem por objetivo problematizar os processos de reconhecimento dos Cursos Superiores de Tecnologia em Gestão Pública do Instituto Federal Farroupilha, considerando as normativas do Sistema Nacional de Avaliação da Educação Superior. Foi realizada uma investigação do tipo estudo de caso apoiado em entrevista semiestruturada, subsidiada pela fundamentação teórica de autores, legislação específica, entre outros. Constatou-se que os programas implantados pelo MEC, em cada momento propício, tiveram contribuições importantes e positivas de acordo com o contexto da época de sua vigência. Verificou-se, a respeito das questões sobre o processo de avaliação de cursos, que o sistema tem como prioridade a transparência para a melhoria contínua do processo e uma necessidade de análise crítica dos seus resultados por parte da instituição.
\end{abstract}

PALAVRAS-CHAVE: Educação superior. Regulação. Avaliação de cursos.

ABSTRACT: This paper and to presents the phases of the process for requesting recognition of the Degree Courses of Technology in Public Management of the Federal Institute Farroupilha, considering the regulations of the e-MEC's platform. A case-study investigation was conducted with a semi-structured interview and subsidized by the theoretical basis of authors, specific legislation, among others. . It was verified that the programs implemented by the MEC, at each favorable moment, had important and positive contributions according to the context of the time of its validity. It was verified that, in respect of the questions about the process of course evaluation, the system has the transparency as priority for the continuous improvement of the process, however, the study showed some difficulties of insertion of data in the e-MEC platform and the rigidity of the process regarding the deadlines of each phase.

KEYWORDS: Degree education. Regulation. Course evaluation.

RESUMEN: Este artículo tiene el objetivo de problematizar los procesos de reconocimiento de las carreras Superiores de Tecnología en Gestión Pública del Instituto Federal Farroupilha, considerando las normativas del Sistema Nacional de Evaluación de la Educación Superior. Se realizó una investigación del tipo estudio de caso apoyado en entrevista semiestructurada, subsidiada por la fundamentación teórica de autores, legislación específica, entre otros. Se constató que los programas implantados por el MEC, en cada momento propicio, tuvieron contribuciones importantes y positivas de acuerdo con el contexto de la época de su vigencia. Se verificó que, con respecto a las cuestiones relativas al proceso de evaluación de carreras, el sistema tiene como prioridad la transparencia para la mejora continua del proceso y la necesidad de una revisión crítica de los resultados por la instituición

PALABRAS CLAVE: Educación superior. Regulación. Evaluación de carreras.

Submetido em: 17/04/2018 - Aceito em: 03/07/2018 - Publicado em: 19/07/2018

\begin{tabular}{|l|c|c|c|c|c|}
\hline (C) Rev. Inter. Educ. Sup. & Campinas, SP & v.4 & n.3 & p.685-702 & set./dez. 2018 \\
\hline
\end{tabular}




\section{INTRODUÇÃO}

O presente artigo apresenta um recorte da tese de Doutorado em Educação. A proposta deste estudo foi produzida e integrada com o apoio e interlocução do Grupo de Estudos e Pesquisa Elos $^{2}$, da Universidade Federal de Santa Maria (UFSM), linha de pesquisa LP2 - Práticas Escolares e Políticas Públicas do Programa de Pós-Graduação em Educação (PPGE) da UFSM, do qual sou integrante e participo como pesquisador, contribuindo com trabalhos na área de avaliação externa de cursos superiores no contexto da internacionalização.

A avaliação da educação superior no Brasil é considerada uma política pública que prima pela qualidade educativa. É uma proposta instituída pelo Ministério da Educação (MEC) e estrutura-se no tripé "regulação - supervisão - avaliação", envolvendo processos e ações muitas vezes distintos, porém intrinsecamente ligados (BRASIL, 2004a).

Para fundamentar o tripé, tem-se como base o Decreto $\mathrm{n}^{\circ} 5.773$ de 9 de maio de 2006, Art. $1^{\circ}$ que estabelece o tripé: regulação, supervisão e avaliação (BRASIL, 2006). Este Decreto foi revogado em 2017 pelo Decreto $n^{\circ} 9.235$ de 15 de dezembro de 2017, porém mantendo o tripé estabelecido.

Entende-se que os processos estão regidos pelas normativas estabelecidas pelo MEC, constituído como Estado regulador, que trabalha para estabelecer subsídios para avaliar as Instituições da Educação Superior (IES); os cursos superiores; e o Exame Nacional de Desempenho dos Estudantes (ENADE), com a finalidade de buscar resultados satisfatórios, visando a melhoria de qualidade da educação superior.

Dentre os documentos legais para o reconhecimento de curso, além do Decreto $\mathrm{n}^{\circ} 5.773$, de 09 de maio de 2006, que trata das funções de regulação, supervisão no sistema federal de ensino (BRASIL, 2006); tem-se a Portaria Normativa $n^{\circ}$ 40, de 12 de dezembro de 2007, cuja finalidade é instituir o e-MEC, sistema eletrônico de fluxo de trabalho e gerenciamento de informações relativas aos processos de regulação, avaliação e supervisão da educação superior no sistema federal de educação (BRASIL, 2007).

Evidencia-se a participação do MEC como órgão responsável pela regulação via Secretaria de Regulação e Supervisão da Educação Superior (Seres), que se articula ao Instituto Nacional de Estudos e Pesquisas Educacionais Anísio Teixeira (INEP) responsável pela parte do processo de avaliação dentro do processo de reconhecimento de cursos.

\footnotetext{
${ }^{2}$ Coordenado pela professora Dr ${ }^{\mathrm{a}}$ Rosane Carneiro Sarturi. Líder do Grupo de Pesquisa ELOS da Universidade Federal de Santa Maria (UFSM), que abarca investigações do campo curricular, perpassado pelas políticas públicas e práticas educativas no ensino básico e avaliação de curso superior no contexto da internacionalização. \begin{tabular}{l|c|c|c|c|c} 
(C) Rev. Inter. Educ. Sup. & Campinas, SP & v.4 & n.3 & p.685-702 & set./dez. 2018
\end{tabular}
} 
De acordo com a Portaria $\mathrm{n}^{\circ} 2.051$, de 9 de julho de 2004, Art. $2^{\text {o }}$ :

[...] o Sistema Nacional de Avaliação da Educação Superior (SINAES) promoverá a avaliação das instituições de educação superior, de cursos de graduação e de desempenho acadêmico de seus estudantes sob a coordenação e supervisão da Comissão Nacional de Avaliação da Educação Superior (CONAES). (BRASIL, 2004b).

Entende-se, assim, que o Estado tem a competência de regular; e o Sistema Nacional de Avaliação da Educação Superior (SINAES) é a Lei que estabelece este processo, a partir das instâncias que atuam com papéis definidos: Comissão Nacional de Avaliação da Educação Superior (CONAES): Coordenar o processo de avaliação; INEP: executar o processo de avaliação; e MEC via Seres atuar na regulação e supervisão. A partir da compreensão destes papéis definidos, problematizou-se por meio de um caso, como estes processos podem ser conduzidos na prática? Que expectativas geram na instituição? Como este processo produz qualidade que é uma das finalidades da avaliação? Entre regulação e qualidade como estão presentes estas finalidades do SINAES no processo de avaliação para fins de reconhecimento de um Curso Superior de Tecnologia em Gestão Pública (CSTGP)?

Diante disso, tem-se como objetivo problematizar os processos de reconhecimento do Curso Superior de Tecnologia em Gestão Pública do Instituto Federal Farroupilha (IFFar), considerando as normativas do Sistema Nacional de Avaliação da Educação Superior.

Para chegar-se aos caminhos pretendidos, realizou-se uma investigação do tipo estudo de caso. De acordo com Yin (2005), o estudo de caso pode ser utilizado com o intuito de levantar questões e hipóteses na pesquisa realizada. Tem-se como caso o Curso Superior de Tecnologia em Gestão Pública do Instituto Federal Farroupilha e seu processo de avaliação. É um curso ofertado no Campus de São Vicente do Sul, Rio Grande do Sul, criado em 2009, reconhecido em 2014.

Com a intenção de elucidar os fatos do contexto de reconhecimento do CSTGP, e o que este processo de avaliação gera, como repercute em uma instituição, a base teórica conceitual originou-se principalmente pelos autores Barreyro e Rothen (2008), Ristoff (1997), Bastos (2015) e Yin (2005). E para a fundamentação documental foram utilizados: leis, portarias, decretos e o relatório de avaliação do reconhecimento do curso.

Com o propósito de apresentar os resultados da pesquisa, tomou-se como instrumento de coleta de dados uma entrevista semiestruturadas com uma servidora do IFFar ${ }^{3}$, atuante nas questões de avaliação na instituição na Função de Diretora de Graduação da Pró-Reitoria de Ensino (PROEN) do Instituto Federal Farroupilha (IFFar). Além disso incorporou-se aspectos

${ }^{3}$ DE CONTO, Janete Maria. Entrevista concedida pela Diretora de Graduação do Instituto Federal Farroupilha - IFFar, Santa Maria/RS, 18 abr. 2018.

\begin{tabular}{l|l|l|l|l|l} 
(C) Rev. Inter. Educ. Sup. & Campinas, SP & v.4 & n.3 & p.685-702 & set./dez. 2018 \\
\hline
\end{tabular}


vivenciados pelo autor como Coordenador do Curso Superior de Tecnologia em Gestão Pública no período de 2011-2014 vivenciando o momento de visita de avaliação para fins de reconhecimento do curso.

Considerando a relevância do tema abordado para a qualidade do processo de avaliação de cursos superiores, espera-se que os subsídios fornecidos neste estudo possam provocar debates acerca da efetividade dos trâmites legais com relação à avaliação nos processos de reconhecimento do CSTGP, do IFFar, no intuito de refletir sobre a eficácia do processo.

\section{CONCEPÇÃO dO MARCO REgULATÓRIO DO SISTEMA NACIONAL DE AVALIAÇÃ̃O DA EDUCAÇÃO SUPERIOR (SINAES)}

Os processos de avaliação de cursos no contexto emergente têm sido destaque como ferramenta de gestão e accountability ${ }^{4}$, buscando resultados no que se refere à qualidade da educação superior. Para entender a proposta do SINAES nas fases do processo de solicitação de avaliação das IES e cursos de graduação, é importante conhecer a concepção e as propostas dos programas que os antecederam.

De acordo com Barreyro e Rothen (2008), as primeiras tratativas do processo de avaliação, propriamente dito, surgiram em 1983, com a criação do Programa de Avaliação da Reforma Universitária (PARU). Esse programa teve como objetivo avaliar o ensino, produzindo um diagnóstico sobre a gestão das instituições e o contexto de realização de atividades de produção e disseminação de conhecimento, subsidiando comparações e evidenciando as singularidades de cada IES.

Com a perspectiva de consolidar o processo de avaliação, no ano de 1985 foi criada a Comissão Nacional de Reformulação da Educação Superior (CNRES), visando à reformulação do ensino superior. A Comissão apresentou ao MEC seu relatório intitulado "Uma nova política para a educação superior brasileira" (BARREYRO; ROTHEN, 2008). Esse trabalho provocou discussões que resultaram em um novo modelo de educação superior, fato motivador na implantação do Programa Nova Universidade, com o Relatório do Grupo Executivo para a Reformulação da Educação Superior (GERES), em 1986, cujo objetivo era apoiar as IES na melhoria da qualidade do ensino.

Ainda, com a proposta de priorizar uma educação de qualidade, foi criado o Exame Nacional de Cursos (ENC), mais conhecido como provão. O objetivo do ENC, era de acompanhar a qualidade do ensino superior no país através de índices que calculassem o rendimento dos estudantes. No entanto, foi extinto por apresentar críticas referentes à credibilidade dos resultados do processo (BARREYRO; ROTHEN, 2008).

\footnotetext{
${ }^{4}$ Transparência, prestação de contas e responsabilização dos agentes públicos perante a sociedade. (AKKARI,
} 2011).

\begin{tabular}{|l|c|c|c|c|c|}
\hline (C) Rev. Inter. Educ. Sup. & Campinas, SP & v.4 & n.3 & p.685-702 & set./dez. 2018 \\
\hline
\end{tabular}


Em 1993, surgiu o Programa de Avaliação Institucional das Universidades Brasileiras (PAIUB), com o propósito de estabelecer diretrizes para a avaliação das universidades (BARREYRO; ROTHEN, 2008). Sua ênfase recaiu nas estratégias de políticas educacionais para avaliação, visando mudanças percebidas como necessárias, considerando que o ENC havia sofrido inúmeras críticas, principalmente por ser uma avaliação muito mais de resultado do que de processo, o PAIUB tinha outras características como a participação voluntária, a avaliação processual e formativa. Entretanto a iniciativa do PAIUB deixou de ter apoio do próprio Ministério da Educação e posteriormente findou.

Reafirmaram-se até o momento as contribuições dos programas antecessores ao atual SINAES para uma reflexão sobre as melhorias da qualidade da educação. Para Ristoff (1997), o PAIUB, que tinha como objetivo o aperfeiçoamento contínuo da qualidade acadêmica e a melhoria do planejamento da gestão universitária, foi fundamental no processo de avaliação. Assim, entende-se que os programas foram necessários para a época vigente, porém extintos por não apresentarem a efetividade esperada.

Com objetivo de entender a proposta do PARU até o PAIUB, questionou-se a entrevistada sobre a relevância dos programas, no contexto da avaliação. A entrevistada relatou: parece mais interessante a proposta do PAIUB, devido aos princípios estabelecidos que se buscou instituir, dentre eles o respeito à identidade institucional (o que é bastante delicado, hoje, com o SINAES), a tentativa de ser um processo não punitivo, a adesão voluntária (no SINAES, há obrigatoriedade, e quando a IES não cumpre os prazos, é punida) e poderá desencadear um problema na continuidade do processo. Já evidenciando aspectos do caráter processual, evidenciando um processo que é cunhado por uma organização, previsto por etapas, normatizado.

Constatou-se que o PAUIB foi um programa que inspirou a implantação do SINAES, no entanto, o atual sistema necessita de uma avaliação no que se refere à articulação do processo de solicitação de avaliação de cursos superiores. Trevisan (2014), constatou que dos programas implantados, o PAIUB apresentou relevantes experiências de base para a instituição do SINAES.

Quadro 1. Programas e ações de avaliação que precederam o SINAES

\begin{tabular}{|c|c|c|c|c|}
\hline Ano & Programa & Propositores & Objetivo/ Ação & $\begin{array}{c}\text { Função/ } \\
\text { concepção } \\
\text { de avaliação }\end{array}$ \\
\hline 1983 & $\begin{array}{ll}\text { Programa } & \text { de } \\
\text { Avaliação } & \text { da } \\
\text { Reforma } & \\
\text { Universitária (PARU) }\end{array}$ & $\begin{array}{l}\text { Desenvolvido } r \text { por } \\
\text { iniciativa do Conselho } \\
\text { Federal de Educação. }\end{array}$ & $\begin{array}{l}\text { Pesquisar o impacto da Lei n. } \\
5.540 / 1968 \text { na gestão e } \\
\text { disseminação do conhecimento } \\
\text { nas instituições. }\end{array}$ & Formativa \\
\hline 1985 & $\begin{array}{lr}\text { Comissão } & \text { Nacional } \\
\text { de Reformulação da } \\
\text { Educação } & \text { Superior } \\
\text { (CNRES) } & \\
\end{array}$ & $\begin{array}{l}\text { Instituído pelo Decreto } \\
\mathrm{n}^{\circ} .91 .177 / 1985 \text {, durante } \\
\text { o governo de José } \\
\text { Sarney. }\end{array}$ & $\begin{array}{l}\text { Propor uma política para a } \\
\text { educação superior vinculando o } \\
\text { financiamento da universidade } \\
\text { ao desempenho nas avaliações. }\end{array}$ & Regulatória \\
\hline
\end{tabular}




\begin{tabular}{|c|l|l|l|l|c|}
\hline 1986 & $\begin{array}{l}\text { Relatório do Grupo } \\
\text { Executivo para a a } \\
\text { Reformulação da } \\
\text { Educação Superior } \\
\text { GERES) }\end{array}$ & $\begin{array}{l}\text { Grupo interno do MEC, } \\
\text { composto por cinco } \\
\text { pessoas. }\end{array}$ & $\begin{array}{l}\text { Formular uma proposta de } \\
\text { Reforma } \\
\text { vinculando o financiamento à } \\
\text { avaliação. }\end{array}$ & Regulatória \\
\hline 1993 & $\begin{array}{l}\text { Programa } \\
\text { Avaliação } \\
\text { Institucional de das } \\
\text { Universidades } \\
\text { Brasileiras (PAIUB) }\end{array}$ & $\begin{array}{l}\text { Formado por } \\
\text { representantes de IES e } \\
\text { entidades da educação } \\
\text { superior com apoio da } \\
\text { SESu/MEC. }\end{array}$ & $\begin{array}{l}\text { Propor a auto avaliação e } \\
\text { avaliação externa envolvendo a } \\
\text { missão institucional da } \\
\text { universidade na sociedade. }\end{array}$ & Formativa \\
\hline
\end{tabular}

Fonte: Adaptado da obra de Barreyro e Rothen (2008), por Trevisan (2014, p. 43).

Após conhecer as experiências dos programas anteriores, com a efetivação de legislações que exigiam uma postura de Regulação por parte do Estado, propôs-se um novo modelo de avaliação da educação superior. Assim, em 2004, foi criado pela Lei no 10.861, de 14 de abril de 2004, o SINAES (BRASIL, 2004a), tendo como finalidade:

[...] a melhoria da qualidade da educação superior, a orientação da expansão da sua oferta, o aumento permanente da sua eficácia institucional e efetividade acadêmica e social e, especialmente, a promoção do aprofundamento dos compromissos e responsabilidades sociais das instituições de educação superior, por meio da valorização de sua missão pública, da promoção dos valores democráticos, do respeito à diferença e à diversidade, da afirmação da autonomia e da identidade institucional. (BRASIL, 2004).

Com a intenção de esclarecer a proposta da concepção e a função do SINAES, apresenta-se na figura 1, o marco regulatório base para a Lei do SINAES, e os tipos de processos de avaliação.

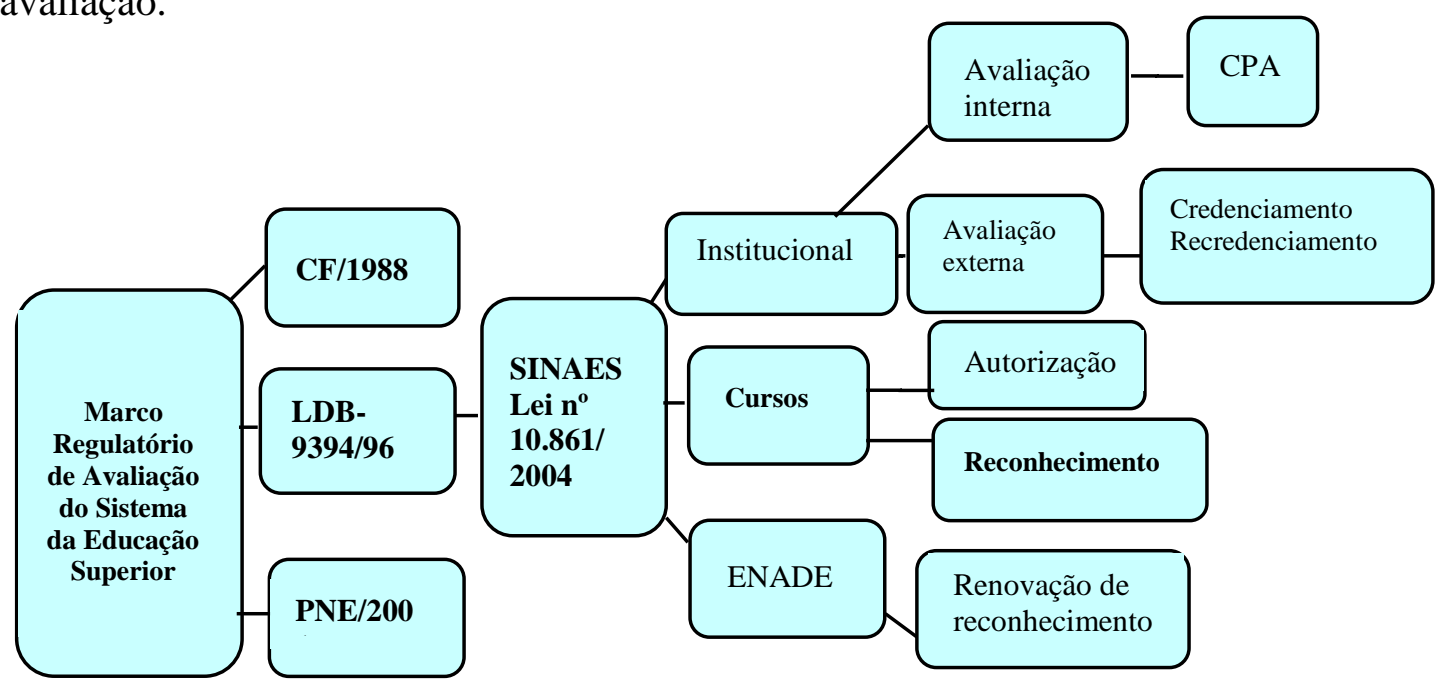

Figura 1. Marco Regulatório de Avaliação, a concepção do SINAES e os processos de avaliação de reconhecimento

Fonte: elaborado pelos autores, adaptados da Constituição Federal (1988); Lei de Diretrizes e Bases da Educação Nacional (LDB) - lei no 9.394/96 (BRASIL, 1996); Plano Nacional da Educação (PNE) (2001); lei $n^{\circ} 10.861$ de 2004 (BRASIL, 2004a).

\begin{tabular}{l|l|l|l|l|l} 
(C) Rev. Inter. Educ. Sup. & Campinas, SP & v.4 & n.3 & p.685-702 & set./dez. 2018
\end{tabular}


De acordo com a figura 1, a base legal do marco regulatório para a proposta do SINAES fundamenta-se, inicialmente na Constituição Federal de 1988. Confirma-se no Art. 209, que a educação foi concedida à possibilidade de oferta por parte da iniciativa privada, mas submetida à autorização e avaliação de qualidade pelo poder público, mediante as seguintes condições: I - cumprimento das normas gerais da educação nacional; II - autorização e avaliação de qualidade pelo Poder Público (BRASIL, 1988).

Ainda, a Constituição Federal de 1988, fundamentou a garantia da avaliação com qualidade, buscando respaldo por meio da implantação de políticas públicas. Diante disso, a Lei $\mathrm{n}^{\circ}$ 9.394, de 20 de dezembro de 1996, Lei de Diretrizes e Bases da Educação (LDB) (BRASIL, 1996), Art. $9^{\circ}$ cujo inciso IX, esclarecer que:

[...] cabe ao governo federal autorizar, reconhecer, credenciar, supervisionar e avaliar cursos e instituições de educação superior.

Inciso VI - assegurar processo nacional de avaliação do rendimento escolar [...], e o artigo 46 fixou que os cursos estariam sujeitos à autorização e ao reconhecimento periódico, bem como o credenciamento de instituições de educação superior. (BRASIL, 1996).

Além da Constituição Federal de 1988 e a LDB, a Lei no 9.394/96 (1996) busca suporte na orientação das legislações do Plano Nacional da Educação (PNE), proposto em 2001. O PNE, instituído pela Lei $\mathrm{n}^{\mathrm{o}} 10.172$, de 9 de janeiro de 2001, fixou a meta 6 para a educação superior. Essa meta consistia na institucionalização de um sistema de avaliação provedor da melhoria da qualidade do ensino, da pesquisa, da extensão e da gestão acadêmica (BRASIL, 2001).

Com base na figura 1, a Lei do SINAES (BRASIL, 2004a), apresenta os três tipos de avaliação para cursos superiores:

- Para autorização: essa avaliação é realizada quando uma instituição solicita autorização ao MEC para constituir um curso, ela é visitada in loco por dois avaliadores, sorteados entre os cadastrados no Banco Nacional de Avaliadores (BASis). Os avaliadores seguem os parâmetros de um instrumento próprio que orienta as visitas. São avaliadas as três dimensões: organização didático-pedagógica; corpo docente e técnico-administrativo; e instalações físicas. As universidades e centros universitários, que são instituições com autonomia, não precisam requerer autorização (exceto para os cursos de Medicina, Odontologia, Psicologia e Direito, que necessitam de autorização prévia, e cursos que funcionarão em campi situados fora do município-sede da instituição).

- Para reconhecimento de curso superior: quando a primeira turma do novo curso completa entre $50 \%$ e $75 \%$ de sua carga horária, a instituição deve solicitar seu reconhecimento ao MEC. É instaurada, então, uma segunda avaliação para verificar se foi cumprido o projeto apresentado para autorização. O reconhecimento de curso é condição necessária para a validade nacional dos respectivos diplomas. 
- Para renovação de reconhecimento: essa avaliação é realizada de acordo com o ciclo do SINAES, ou seja, a cada três anos. Na análise, o MEC considera os resultados obtidos pelo curso nas avaliações. Os cursos que obtiverem Conceito Preliminar de Curso (CPC) 1 ou 2 serão avaliados in loco. Se o conceito insuficiente for confirmado, o MEC poderá dar início ao processo de supervisão.

Apresentado os tipos de avaliação dos cursos superiores, fica definida a competência da Secretaria de Regulação e Supervisão da Educação Superior (Seres), criada pelo Decreto $\mathrm{n}^{\circ}$ 7.480, de 17 de abril de 2011, da responsabilidade pela regulação e supervisão de IES; dos cursos superiores de graduação na modalidade presencial e a distância (BRASIL, 2011).

No que se refere ao ENADE, o objetivo é avaliar o desempenho dos estudantes com relação ao aproveitamento dos conteúdos das disciplinas, o desenvolvimento de competências e habilidades necessárias ao aprofundamento da formação geral e profissional, e o nível de atualização dos estudantes com relação à realidade brasileira e mundial, integrando o SINAES (BARREYRO; ROTHEN, 2008).

Destaca-se que, para esta pesquisa, a abordagem é especificamente relacionada ao processo de avaliação para reconhecimento dos Cursos Superiores de Tecnologia. Desse modo, para respaldar esta proposta, perguntou-se para a entrevistada: quais os programas que contribuíram para a melhoria da educação superior? Resposta: de modo geral, penso que sejam as contribuições do SINAES para a melhoria da qualidade da educação superior no Brasil, tendo em vista a obrigatoriedade, para as IES, de cumprimento dos requisitos legais e normativos dos cursos superiores, relacionadas às dimensões avaliadas no âmbito do Sistema. A Seres também tem responsabilidade de regulação no processo de reconhecimento de curso.

Diante da resposta suscita a questão relacionada a regulação, o que se entende por regulação para o SINAES e o que se entende por regulação, a partir de autores que investigam a temática, onde a regulação e a avaliação se relacionam, visto que a regulação está prevista como finalidade do SINAES: regular e induzir qualidade. Correntemente imputa-se a Seres e no seu próprio nome a questão da regulação, que está relacionada aos atos de autorização, reconhecimento e renovação de reconhecimento para cursos de graduação e de credenciamento e recredenciamento para Instituição de Educação Superior (IES).

Porém estes processos são previstos na Lei do SINAES (BRASIL, 2004a), e no Decreto $\mathrm{n}^{\circ}$ 5.773. Com a revogação do Decreto $n^{\circ} 5.773$, de 9 de maio de 2006, pelo Decreto $n^{\circ} 9.235$, de 15 de dezembro de 2017 (BRASIL, 2018) redefine-se a regulação que é relacionada aos atos administrativos mas que em 2017 passa a ser ampliada conforme é possível observar: "A Regulação será realizada por meio de atos administrativos do funcionamento de instituições de educação superior e de cursos de graduação e sequenciais" (BRASIL, 2006). E a partir de 2017:

\begin{tabular}{l|l|l|l|l|l|}
\hline (C) Rev. Inter. Educ. Sup. & Campinas, SP & v.4 & n.3 & p.685-702 & set./dez. 2018 \\
\hline
\end{tabular}




\begin{abstract}
A regulação será realizada por meio de atos autorizativos de funcionamento de IES e de oferta de cursos superiores de graduação e de pós-graduação lato sensu no sistema federal de ensino, a fim de promover a igualdade de condições de acesso, de garantir o padrão de qualidade das instituições e dos cursos e de estimular o pluralismo de ideias e de concepções pedagógicas e a coexistência de instituições públicas e privadas de ensino. (BRASIL, 2018).
\end{abstract}

Com este Decreto amplia-se a concepção de regulação e reafirma-se a coexistência de IES públicas e privadas no sistema de educação superior, ambos com a mesma avaliação estatal e com a reafirmação de garantia de padrão de qualidade.

Mas além de se relacionar o termo regulação à legislação nacional, termo que no Brasil também expressa os atos administrativos regulatórios, a expressão regulação, segundo Barroso (2005) aproxima-se aos processos de controle exercidos por organismos multilaterais, pelo Estado e em diversos níveis de gestão, mas não se confunde com regulamentação:

[...] O processo de regulação compreende, não só, a produção de regras (normas, injunções, constrangimentos etc.) que orientam o funcionamento do sistema, mas também o (re) ajustamento da diversidade de acções dos actores em função dessas mesmas regras.

Num sistema social complexo (como é o sistema educativo) existe uma pluralidade de fontes (centro/periferia, interno/externo, actor A/actor B etc.), de finalidades e modalidades de regulação, em função da diversidade dos actores envolvidos, das suas posições, dos seus interesses e estratégias. (BARROSO, 2005, p. 733).

Assim sendo, tanto a regulação quanto a qualidade estão presentes num processo de reconhecimento de curso, ao descrever este processo no caso pesquisado é possível observar como elas se evidenciam a partir da apresentação dos trâmites legais que sustentam a solicitação de reconhecimento dos CSTGP do IFFar e do que este processo evoca no curso.

Para Barroso (2005), o Estado pode ser considerado como avaliador e regulador na medida em que passa a fazer cada vez menos as tarefas e ações cotidianas, funções por vezes transferidas a entes privados, e assim focando-se cada vez mais num papel de monitoria e avaliação de resultados, num contexto de Nova Gestão Pública, ancorando-se na ideia de eficiência e eficácia.

\title{
FASES DAS ETAPAS DO PROCESSO DE SOLICITAÇ̃̃o DE RECONHECIMENTO DOS CURSOS SUPERIORES DE TECNOLOGIA E SUAS REPERCUSSÕES
}

A solicitação da visita in loco para o reconhecimento dos cursos superiores obedece a trâmites e legislação específicas. Desse modo, a articulação para a solicitação de avaliação de cursos de graduação é realizada exclusivamente por meio eletrônico, no sistema e-MEC, e

\begin{tabular}{|l|c|c|c|c|c|}
\hline C Rev. Inter. Educ. Sup. & Campinas, SP & v.4 & n.3 & p.685-702 & set./dez. 2018 \\
\hline
\end{tabular}


observa as disposições legais pela Portaria Normativa $n^{\circ}$ 40, de 12 de dezembro de 2007 (BRASIL, 2007).

Buscando entender o processo, como normativa orientadora, o Art. 28 da Portaria $\mathrm{n}^{\circ}$ 40, de 12 de dezembro de 2007, estabelece que nos processos de autorização e reconhecimento, dos cursos de tecnologia, o requerente institucional informará o eixo em que o curso está inserido, observando o Catálogo Nacional dos Cursos Tecnológicos (BRASIL, 2007).

Analisando as legislações já apresentadas nesse estudo, destaca-se que as informações para o sistema e-Mec devem estar de acordo com o instrumento de avaliação dos cursos de graduação. Os itens verificados contemplam: $1^{\mathrm{a}}$ - Organização didático-pedagógica; $2^{\mathrm{a}}$ Corpo docente e tutorial; $3^{\mathrm{a}}$ - Infraestrutura, indicadores que são avaliados por conceitos de 1 a 5 (BRASIL, 2017). Diante disso, o processo de solicitação de avaliação para reconhecimento de curso passa por algumas fases, tendo como base os prazos estipulados legalmente.

Assim, de acordo com a portaria $n^{\circ} 40$, de 12 de dezembro de 2007, $\S 3^{\circ}$ diz que:

[...] a contagem de prazos observará o disposto no art. 66 da Lei $\mathrm{n}^{\circ} 9.784$, de 1999, em dias corridos, excluído o dia da abertura da vista e incluído o do vencimento, levando em consideração o horário de disponibilidade do sistema, que será devidamente informado aos usuários. (BRASIL, 2007).

O planejamento e a documentação legal para a solicitação de avaliação de reconhecimento são de competência do coordenador do curso, que deve articular o processo com algumas possibilidades de autonomia e acompanhar todos os procedimentos, inclusive no ato da visita in loco (BASTOS, 2015). Com base nessas informações é pertinente apresentar as quatro etapas do processo de solicitação de avaliação para o reconhecimento dos CSTGP do IFFar, objeto desta pesquisa.

Bastos (2015) destaca que, na $1^{\text {a }}$ fase solicita-se a abertura do processo exclusivamente em meio eletrônico do sistema do e-MEC. Assim orientado:

[...] $\S 2^{\circ} \mathrm{O}$ acesso ao sistema, para inserção de dados pelos agentes públicos competentes para atuar nos processos de regulação e avaliação também se dará pela atribuição de chave de identificação e senha de acesso, pessoal e intransferível, com a celebração de termo de compromisso.

$\S 3^{\circ} \mathrm{O}$ acesso ao e-MEC deverá ser realizado com certificação digital, padrão ICP Brasil, com o uso de Certificado tipo A3 ou superior, emitido por Autoridade Certificadora credenciada, na forma da legislação específica. (BRASIL, 2007).

Para o protocolo de processo de autorização de curso, o Procurador Institucional (PI) previamente cadastrado no e-MEC deverá acessar o endereço http://emec.mec.gov.br/ies. Apresenta-se a tela de acesso ao Sistema e-Mec (Figura 2). 


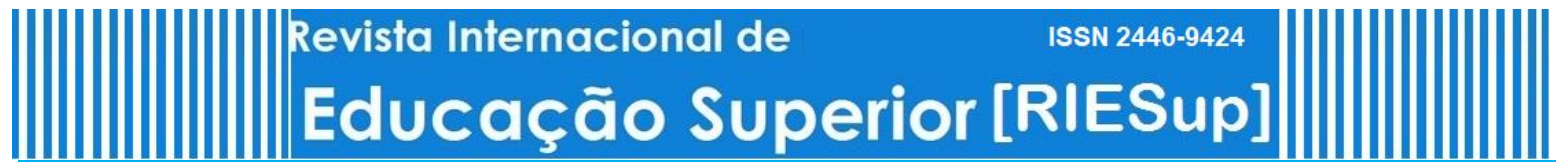 \\ Artigo

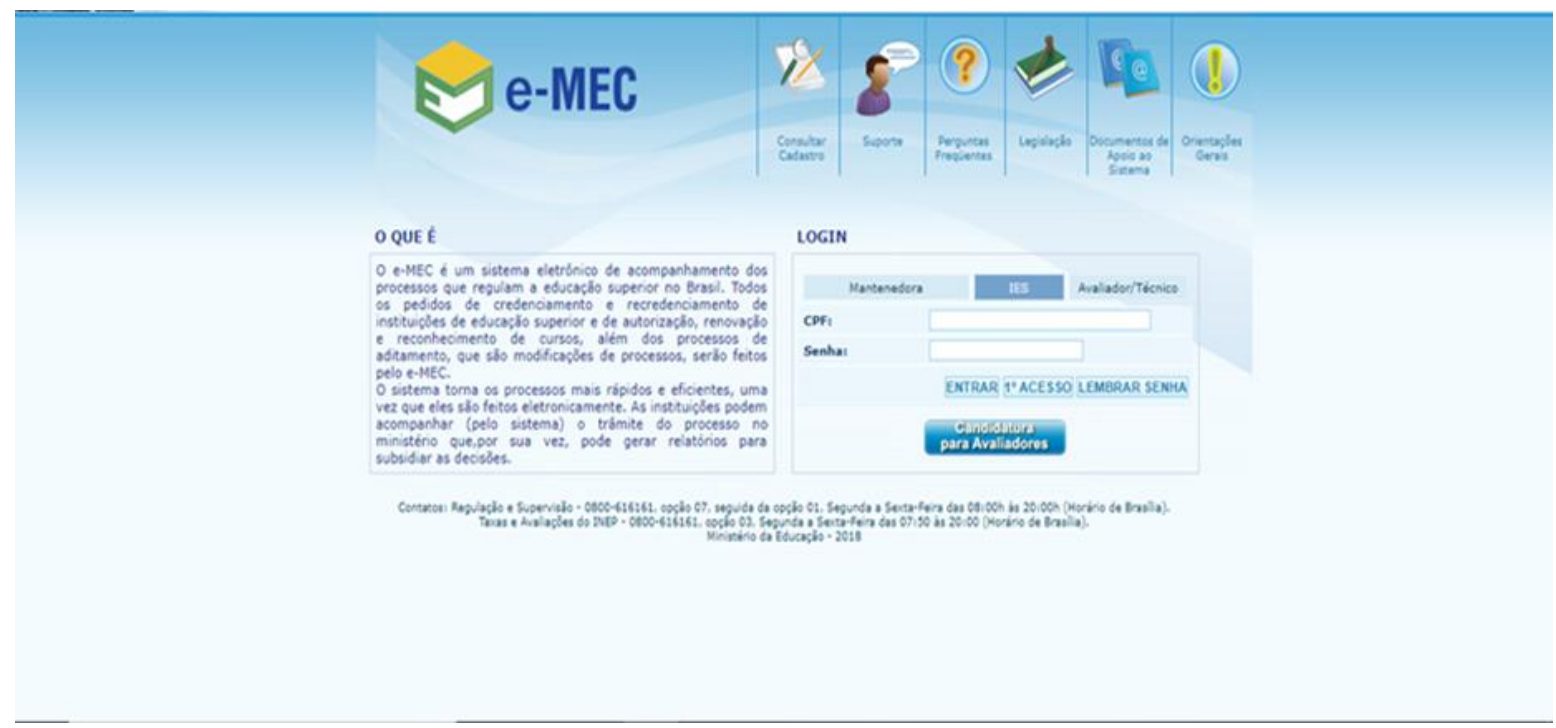

Figura 2. Tela de acesso ao Sistema e-MEC (perfil IES)

Fonte: Disponível em:〈http://emec.mec.gov.br/documentospublicos/Manuais/40.pdf〉.

No período agendado para a abertura do processo na plataforma do e-MEC, o PI informa na plataforma do e-Mec os dados da Mantenedora, da Mantida, do Corpo Dirigente, dos Membros da Comissão Própria de Avaliação (CPA) - Formulário e informações do Projeto Pedagógico de Curso (PPC), tais como: 1. Perfil do Curso; 2. Atividades; 3. Perfil do Egresso; 4. Forma de Acesso; 5. Representação Gráfica de um Perfil de Formação (Perfil Etnográfico); 6. Sistema de Avaliação do Processo de Ensino-Aprendizagem; 7. Sistema de Avaliação do Projeto do Curso; 8. Trabalho de Conclusão de Curso (TCC); 9. Estágio Curricular ou Prática Profissional Integrada (conforme opção do curso); e 10. Ato autorizativo do curso; do Detalhamento do curso; e do Andamento do processo/Histórico (BASTOS, 2015).

Os campos Mantenedora, Mantida, corpo dirigente e membros da CPA contemplam dados institucionais já preenchidos pelo Pesquisador Institucional (PI), como: razão social, Cadastro Nacional de Pessoa Jurídica (CNPJ), endereço, nome do PI, dados dos dirigentes (Reitoria e Pró-Reitorias), relatórios e informações sobre os membros da CPA. Com referência aos componentes curriculares, devem ser esclarecidos, especificando o período da oferta, carga horária, descrição da ementa e objetivos, e as bibliografias básica e complementar (BRASIL, 2017).

Quando é requerido o pedido de reconhecimento dos cursos, o gestor acadêmico e o PI informam os dados solicitados na plataforma do e-MEC, sempre acatando os prazos que são estipulados, para não sofrer as penalidades que são impostas, como por exemplo, a suspensão do processo. Os dados informados para o sistema e-MEC, devem estar de acordo com os itens do instrumento de avaliação. Os avaliadores consideram as seguintes orientações: 
[...] 1. Atribuir conceitos de 1 a 5, em ordem crescente de excelência, a cada um dos indicadores de cada uma das três dimensões;

2. Considerar os critérios de análise dos respectivos indicadores da dimensão;

3. Atribuir os conceitos a cada um dos indicadores. Os conceitos deverão ser justificados, com argumentação qualitativa e contextualizados, com base nos indicadores;

4. Assegurar a coerência dos conceitos atribuídos aos indicadores com as suas respectivas justificativas (análise quantitativa e análise qualitativa). (BRASIL, 2017).

Para instruir a primeira fase do processo é importante a gestão entre PI e coordenador de curso, que são os responsáveis por prestar as informações relativas ao projeto pedagógico do curso, a prestação de informações completas desde a abertura do processo facilita as fases posteriores de avaliação. Mas além disso, se bem conduzidas podem auxiliar num processo de reflexão sobre o curso, por parte do coordenador, dos membros do Núcleo Docente Estruturante e da comunidade do curso, na medida em que levam a informar a comissão de avaliadores que neste papel representa o Estado, como o curso desenvolve sua função formadora.

Passando para a $\mathbf{2}^{\mathbf{a}}$ fase do processo, abre o formulário de avaliação e são registrados no eMEC as informações relativas a organização pedagógica, corpo docente e infraestrutura, nesta contém informações de: atributos docentes, tempo de atuação profissional na educação e fora da área, as disciplinas ministradas pelo docente e o número de publicações científicas produzidas nos últimos três anos.

Após a segunda fase, com as informações disponibilizadas no sistema e-MEC, o processo segue para a designação da comissão avaliadora. Na terceira fase ocorre a visitas in loco dos avaliadores. A comissão é composta por dois professores sorteados aleatoriamente entre os cadastrados no Banco Nacional de Avaliadores (BASis), de acordo com a área do curso a ser avaliado. Toda a gestão desta etapa ocorre pelo INEP. As datas em que ocorrerá a visita são comunicadas para a Instituição requerente.

Conforme o Art. 16, da Portaria Normativa n 40, de 12 de dezembro de 2007:

[...] realizada a visita à instituição, a comissão de avaliadores elaborará relatório e parecer, atribuindo conceito de avaliação.

$\S 1^{\circ} \mathrm{O}$ relatório e parecer serão inseridos no e-MEC pelo INEP, notificando-se a instituição e simultaneamente, SESu, SETEC ou SEED, conforme o caso.

$\S 2^{\circ}$ A instituição e as Secretarias terão prazo comum de 60 dias para impugnar o resultado da avaliação.

$\S 3^{\circ}$ Havendo impugnação, será aberto prazo comum de 20 dias para contrarrazões das Secretarias ou da instituição, conforme o caso. (BRASIL, 2007).

Conforme as orientações da Portaria Normativa $\mathrm{n}^{\circ}$ 40, de 12 de dezembro de 2007, após a visita in loco, os avaliadores emitem um relatório e parecer apresentando a nota de cada item do instrumento de avaliação vigente. 
Perguntado para a entrevistada sobre os trâmites legais da terceira fase do processo de avaliação para reconhecimento dos cursos do IFFar, obteve-se a seguinte resposta: encerrando as três fases do processo, na quarta fase, o resultado da avaliação in loco é divulgado através de relatório no sistema e-MEC e enviado aos dirigentes da instituição e do curso. Após a leitura do relatório dos avaliadores, por parte da coordenação do curso e da PROEN, é possível solicitar a impugnação da avaliação, dentro de um prazo de 60 dias a contar a data de publicação dos resultados, caso exista alguma inconsistência na análise realizada pelos avaliadores.

Entende-se, portanto, que para impugnar o processo, esses devem estar fundamentados legalmente em fatos justificáveis. Isso porque às vezes fica difícil discordar dos avaliadores, considerando que existem alguns itens de avaliação com critérios subjetivos, que terminam por destacar o entendimento dos mesmos.

Caso seja solicitada a impugnação, o processo será submetido à Comissão Técnica de Acompanhamento da Avaliação (CTAA), que apreciará as manifestações da instituição e das Secretarias, e decidirá, motivadamente, por uma dentre as seguintes formas:

[...] I - manutenção do parecer da Comissão de Avaliação;

II - reforma do parecer da Comissão de Avaliação, com alteração do conceito, para mais ou para menos, conforme se acolham os argumentos da IES ou da Secretaria, respectivamente;

III - anulação do relatório e parecer, com base em falhas na avaliação, determinando a realização de nova visita, na forma do art. 15 . $§ 1^{\circ}$ A CTAA não efetuará diligências nem verificação in loco, em nenhuma hipótese. § $2^{\circ}$ A decisão da CTAA é irrecorrível, na esfera administrativa, e encerra a fase da avaliação. (BRASIL, 2006).

Diante dessas orientações, será apreciado o resultado do parecer da comissão e confirmada a decisão do resultado do relatório ou anulação da avaliação da comissão. Caso a opção seja pela anulação do relatório, será agendada uma nova visita in loco. Se acatada a nota do relatório, o processo recebe despacho que origina a expedição da portaria de reconhecimento, publicada no Diário Oficial da União (DOU), no caso da avaliação ter alcançado resultado satisfatório, que é de Conceito de Curso três ou mais,

$\mathrm{Na}$ conversa com a entrevistada sobre quais as sugestões que considera importante para a melhoria do processo de solicitação de avaliação de reconhecimento dos cursos superiores (processo e plataforma). A resposta foi: deve ser repensado o processo de solicitação de avaliação de reconhecimento dos cursos. Minha sugestão é referente aos prazos de cadastro dos cursos e preenchimento do formulário eletrônico.

Isso porque, quando o formulário eletrônico abre, na segunda fase do processo, está estabelecido um prazo de quinze dias para o seu preenchimento. Assim, se as informações, não estiverem previamente preparadas para o preenchimento de em média cinquenta 
indicadores, com informações detalhadas sobre o curso, inviabiliza o atendimento do prazo que é exíguo.

De acordo com as narrativas, entende-se que a melhoria tecnológica no processo deve ser prioridade para assegurar a credibilidade do sistema e-MEC, contribuindo para seu aperfeiçoamento continuado. Esta parece uma condição aderente entre as fases do processo e a avaliação com a proposta de supervisão e regulação, consolidando a perspectiva de democratização do ensino superior com qualidade.

Além disso, também cabe a instituição um planejamento de cada fase contendo a preparação prévia do processo de reconhecimento, possibilitando assim compreender a complexidade do processo e sua finalidade. Conforme a experiência de coordenação, observa-se que este planejamento é um diferencial para a melhoria do curso, levando a reflexão sobre fragilidades e potencialidades.

Neste sentido problematizar o que seria qualidade para a realidade de cada curso, considerando o perfil específico de egresso, o contexto educacional onde este curso está localizado, a justificativa e o objetivo do curso, parecem auxiliar a preparação tanto para avaliação, quanto para a contínua promoção de qualidade do curso. Fazer o exercício de questionar junto ao NDE: se nós fossemos os avaliadores, como olharíamos o nosso próprio curso a partir do instrumento de avaliação externa? Este questionamento poderia auxiliar a avaliação, num movimento de autoavaliação e autoregulação.

Durante o processo de reconhecimento, observou-se pelo coordenador do curso as seguintes fragilidades: a dificuldade de reunir e organizar todas as informações que compõe os formulários e a documentação para a visita; a grande expectativa em relação ao que o avaliador vai apontar; será somente relacionada aos requisitos ou terão opiniões mescladas? Mediante esta expectativa, o momento de avaliação tornou-se um momento tenso, mas ao mesmo tempo de aprendizagem e maturidade para o curso e os gestores institucionais, uma vez que a avaliação e a verificação da comissão externa é necessária e também uma baliza da qualidade do curso.

Ainda assim o resultado do Conceito de Curso foi quatro, considerado muito bom, em um conceito que pode variar de um a cinco. Dentre as três dimensões avaliadas, considerou-se a mais desafiadora a organização didático-pedagógica, relacionada aos indicadores justificativa do curso, objetivo e perfil do egresso em que se obteve um resultado aquém do esperado, em que não se demonstrou aos avaliadores a qualidade do curso nestes aspectos.

Quanto ao corpo docente, considerou-se frágil a publicação dos professores no período da avaliação. Isso demonstra tanto a exigência em termos de resultado de publicação, quanto 
uma postura que não era coesa em todo o grupo de docentes em relação a necessidade de publicação contínua.

Na dimensão infraestrutura, observou-se a fragilidade em relação a aquisição de periódicos e livros, considerando o tempo que um curso leva para constituir seu acervo, e mantê-lo atualizado, obedecendo a legislação para compras no serviço público.

Mediante todos estes resultados, considera-se importante tomar a divulgação e discussão dos resultados como uma quarta fase do processo, em que se analise profundamente cada indicador avaliado, o que foi apontado como fragilidade, que ações podem ser tomadas pela coordenação e futuras coordenações do curso, pela direção e pela gestão superior do IFFar.

Considerando o processo de reconhecimento do CSTGP, observa-se que ainda há uma fragilidade em trabalhar com os resultados advindos da avaliação no curso, é um processo que está em andamento, com a necessidade de ser aprofundado. Porém somado a avaliações de outros cursos já provoca modificações induzidas pela gestão como: articulação das Próreitorias de Ensino, de Pesquisa e de Extensão estudando e aprofundando as normativas de avaliação junto aos cursos; organização das secretarias acadêmicas; estabelecimentos de grupos de trabalho para elaboração e revisão das matrizes curriculares dos cursos de graduação e Projetos Políticos; organização dos NDE e Colegiados dos Cursos reunindo os professores relacionados aos eixos que estruturam os cursos, no caso de Gestão Pública denominado Eixo de Gestão e Negócios. Todas estas ações tiveram influências dos processos de reconhecimento dos cursos.

\section{CONSIDERAÇões finais: PRoblematizações entre Regulação e QUALIDADE}

Apresentaram-se as fases do processo para a solicitação de reconhecimento dos Cursos Superiores de Tecnologia em Gestão Pública do Instituto Federal Farroupilha, considerando as normativas do SINAES. Nesse estudo foram analisadas as contribuições dos programas de avaliação, desde a implantação do PARU até o PAIUB, no contexto da avaliação da educação superior. Diante dessa análise, constatou-se que os programas implantados pelo MEC tiveram contribuições importantes de acordo com o contexto da época de sua vigência. Mas, considera-se que dentre os programas, o PAIUB foi o processo de avaliação que trouxe mais resultados positivos, em função do tempo de duração e a articulação de gestão, auxiliando assim, nos resultados da busca da qualidade da educação superior.

Na construção do sistema de avaliação vigente, a partir de 2004, o SINAES, foi organizado e fundamentado essencialmente no conjunto de legislações que demarcam as características de um Estado regulador, conforme as definições de Barroso (2005), e que coadunam com a expressão presente no Decreto 9.235 de 15 de dezembro de 2017 (BRASIL, 2018) reafirmando a necessidade de regular a oferta exercendo um controle por meio da avaliação.

\begin{tabular}{l|c|c|c|c|c} 
(C) Rev. Inter. Educ. Sup. & Campinas, SP & v.4 & n.3 & p.685-702 & set./dez. 2018 \\
\hline
\end{tabular}


Verificou-se na pesquisa que o SINAES tem contribuído para a efetividade do processo regulação, demonstrando transparência e auxiliando por meio de interlocução na tomada de decisão dos gestores da educação superior, gerando ações institucionais que disparam processos de melhoria. Entende-se assim, que o processo está em fase de reestruturação na busca de novas ações de melhoria contínua das políticas públicas educativas, de modo que, a própria avaliação precisa ser constantemente avaliada e aprimorada.

Também foi possível verificar as fragilidades e potencialidades do curso a partir do processo de reconhecimento, verificando as possibilidades de promover continuadamente a autoavaliação.

Com relação às fragilidades técnicas do processo de reconhecimento, foi constatado as dificuldades tecnológicas no momento da postagem de informações no sistema e-MEC, necessidade de planejar antecipadamente as fases do processo, para não perder nenhuma etapa e a organização do curso para o recebimento dos avaliadores. Em relação ao resultado da avaliação considerou-se positivo, e gerou expectativas no grupo envolvido, demonstrando que o processo é mutável e de aprendizado, e se percebe que o SINAES, através das suas articulações e legislações, busca a efetividade nos resultados.

Ficou esclarecida a importância do comprometimento dos agentes públicos, os docentes, discentes, técnicos administrativos e coordenador do curso, na proposta da efetividade do processo, além da Diretora de Graduação da PROEN, que exerce um papel importante na gestão universitária no contexto do IFFar.

Portanto, ao observar detalhadamente as fases do processo de reconhecimento pode-se problematizar como a regulação acontece em seus múltiplos aspectos: regulamentação; gestão do processo de reconhecimento pela Seres, INEP, momento da visita com os avaliadores em articulação com a própria gestão institucional. o que implica também em momentos de tensão e aprendizado. Espera-se que os subsídios fornecidos neste artigo possam provocar novas reflexões acerca das fases do processo de solicitação de avaliação para reconhecimento de cursos superiores de tecnologia e aprofundamento da reflexão sobre regulação e qualidade.

\section{REFERÊNCIAS}

AKKARI, A. Internacionalização das políticas educacionais: transformações e desafios. Petrópolis: Vozes, 2001.

BARREYRO, G. B; ROTHEN, J. C. Para uma história da avaliação da educação superior brasileira: análise dos documentos do Paru, Cnres, Geres e Paiub. Avaliação, Revista da Rede de Avaliação Institucional da Educação Superior, Campinas; Sorocaba, SP, v. 13, n. 1, p. 131-152, mar, 2008. 
BARROSO, João. O Estado, a educação e a regulação das políticas públicas. Educação e Sociedade, Campinas, v.. 26, nº. 92, p. 725-751, Especial. Out. 2005. Disponível em: <http://www.cedes.unicamp.br>. Acesso em: 15 maio 2017.

BASTOS, A. R. B. de. Reconhecimento dos cursos de graduação: orientações gerais / Amélia Rota Borges de Bastos; Daniele Duarte da Cunha; Mônica de Souza Trevisan. - Bagé: Universidade Federal do Pampa, 2015. 94 p.

BRASIL. Constituição da República Federativa do Brasil. Brasília, DF: Senado Federal, 1988.

BRASIL. Lei n9.394, de 20 de dezembro de 1996. Estabelece as diretrizes e bases da educação nacional. Diário Oficial [da] República Federativa do Brasil, Brasília, DF, v. 134, no 248, 23 dez. 1996. Seção I, p. 177-197.

BRASIL. Lei n ${ }^{\circ} 10.861$, de 14 de abril de 2004a. Institui o Sistema Nacional de Avaliação da Educação Superior - SINAES e dá outras providências. Diário Oficial [da] República Federativa do Brasil, Brasília, DF, v.141, n 72, 15 abri. 2004a. Seção I, pp. 3-4.

BRASIL. Lei n 10.172, de 09 de janeiro de 2001. Aprova o Plano Nacional de Educação e dá outras providências. Diário Oficial[da] República Federativa do Brasil. Brasília, DF, v. 139, n 7, 10 jan. 2001. Seção I, p. 27834-27841.

BRASIL. Decreto n ${ }^{\circ} 5.773$, de 9 de maio de 2006. Dispõe sobre o exercício das funções de regulação, supervisão e avaliação de Instituições de Educação Superior e cursos superiores de graduação e sequenciais no sistema federal de ensino. Diário Oficial [da] República Federativa do Brasil, Brasília, DF, v. 143, nº 88, 10 de maio. 2006. Seção I, p. 6-10.

BRASIL. Decreto $\mathbf{n}^{\circ}$ 9.235, de 15 de dezembro de 2017. Dispõe sobre o exercício das funções de regulação, supervisão e avaliação das instituições de educação superior e dos cursos superiores de graduação e de pós-graduação no sistema federal de ensino. Disponível em: <http://www.planalto.gov.br/ccivil_03/_Ato20152018/2017/Decreto/D9235.htm\#art107> Acesso em: 16 jul. 2018.

BRASIL. Decreto n ${ }^{\circ} 7.480$, de 17 de abril de 2011. Secretaria de Regulação e Supervisão da Educação Superior (Seres). absorvendo competências antes da SESu, da Setec e da extinta Seed do Ministério da Educação. Disponível em: <http://portal.mec.gov.br/secretariade-regulacao-e-supervisao-da-educacao-superior-seres >. Acesso em: 10 jan. 2018.

BRASIL. Portaria Normativa $\mathrm{n}^{\circ}$ 40, de 12 de dezembro de 2007. Institui o e-MEC, sistema eletrônico de fluxo de trabalho e gerenciamento de informações relativas aos processos de regulação, avaliação e supervisão de educação superior no sistema federal de educação, e o Cadastro e-Mec de Instituições e Cursos Superiores e consolida disposições sobre indicadores de qualidade, banco de avaliadores (Basis) e o Exame Nacional de Desempenho de Estudantes (ENADE) e outras disposições. Diário Oficial [da] República Federativa do Brasil, Brasília, DF, nº 249, 29 de dez. 2010. Seção 1, p. 23-31. 
BRASIL. Portaria ${ }^{\circ}$ 2.051, de 9 de julho de 2004b. Dispõe sobre o regulamento dos procedimentos de avaliação do Sistema Nacional de Avaliação da Educação Superior (SINAES), instituída na Lei n ${ }^{\circ} 10.861$, de 14 abr. de 2004a.

MINISTÉRIO DA EDUCAÇÃO E CULTURA - MEC. Sistema e-Mec. Manual para preenchimento de processos de autorização de cursos de graduação na modalidade presencial. 2015. Disponível em:

<http://emec.mec.gov.br/documentospublicos/Manuais/40.pdf>. Acesso em: 20 fev. de 2018.

RISTOFF, D. I. Avaliação Institucional e a Mídia. Avaliação. Raies, Campinas, 1997. ano2, n.1(3), p.61-64, mar.

TREVISAN, M. de S. Influências do SINAES na construção curricular do curso de Pedagogia. 2014. 141 p. Dissertação (Mestrado em Educação), Centro de Educação, Programa de Pós-Graduação em Educação. Universidade Federal de Santa Maria, Santa Maria. 2014.

YIN, R. K. Estudo de Caso: planejamento e método. 3. ed. Porto Alegre: Bookman, 2005.

\section{Sobre os autores}

\section{${ }^{1}$ Antônio Carlos Minussi Righes}

E-mail: acmrighes@gmail.com

Universidade Federal de Santa Maria - BRASIL

Doutorando em Educação - Universidade Federal de Santa Maria [UFSM].

${ }^{2}$ Mônica de Souza Trevisan $(\mathbb{D}$

E-mail:monicastrevisan@gmail.com

Universidade Federal de Santa Maria - BRASIL

Doutoranda em Educação - Universidade Federal de Santa Maria [UFSM].

\section{${ }^{3}$ Rosane Carneiro Sarturi ${ }^{(D)}$}

E-mail:rcsarturi@gmail.com

Universidade Federal de Santa Maria - BRASIL

Doutora em Educação - Universidade Federal do Rio Grande do Sul [UFRGS].

\section{${ }^{4}$ Marilene Gabriel Dalla Corte ${ }^{(D)}$}

E-mail: marilenedallacorte@gmail.com

Universidade Federal de Santa Maria - BRASIL

Doutora em Educação - Pontifícia Universidade Católica do Rio Grande do Sul [PUCRS]. 